\title{
THE INFLUENCE OF LEADERSHIP STYLES ON THE EVOLUTION OF ATHLETIC PERFORMANCE
}

\author{
Prof. Ph.D. Roxana ENACHE ${ }^{1}$, Grațiela MARIN ${ }^{2}$, \\ ${ }^{1}$ Technical University of Civil Engineering of Bucharest, Teacher Training Department, \\ ROMANIA, \\ E-mail: ${ }^{1}$ rocatare@yahoo.com, ${ }^{2}$ grati.marin@gmail.com
}

\begin{abstract}
In this research we aim: To identify the psychological mechanisms that enhance the effectiveness of teamwork (i.e., the work coaches, psychologists, sports specialists etc. do with the athletes); To identify the aspects of communication and coach-sportsperson relationships that determine athletic performance; To determine the need to adopt a managerial style, on the part of the coach, that is tailored to the needs of the athletes so that performance is more effective. We combined several research methods in order to accurately identify the needs of the coach, but also those of the athletes, so we applied questionnaires to managers, coaches and athletes, we designed grids to observe behaviours relevant to the performance of athletes, and we applied evaluation grids selecting cardiometabolic and biochemical tests that directly correlate with sporting performance. By assessing the motivational trainability of athletes, using tests including the determination of biochemical phenomena and the optimization of athletes' nutrition, and using individualized motivational techniques and tools, we were able to validate hypotheses such as: if the leadership style is appropriate to the athlete and/or group, then the athletes' performance will be superior; if we apply scientific methods in real time, biochemical testing and cardiometabolic testing, then we provide a higher chance for performance in swimming at European and world level; if the leader finds appropriate motivational methods for each athlete, then evolution of performance will be on an upward trend.
\end{abstract}

Keywords: athletic performance; communication in coaching; leadership style, motivation;

\section{INTRODUCTION. RESEARCH BACKGROUND}

The present micro-research aimed to identify the continuing training needs of sports managers, regardless of where they work: clubs, federations, county directorates. Athletic performance cannot be achieved individually, it requires a team of specialists and cohesion among its members. (FAMOSE, J.-P., 1993)

In this context, the present research has proposed the following objectives: to identify the psychological, motivational, coach-sportsperson communication means in order to achieve maximum performance, to optimize the leadership style in order to achieve maximum athletic performance, to increase the efficiency of sports activity in terms of team effort by both specialists and athletes.

Many specialists believe that it is enough to master notions of management, without taking into account the organisational specifics of each sports structure, or the influence of the internal and external environment in which they operate. (EPURAN, M., HOLDEVICI, I., TONITA, F., 2001) Only in structures where there is a dedicated and trained manager, there can be sporting performance. 


\section{RESEARCH PURPOSE}

The goal of the research is to optimise managerial processes focused on motivating coaches and athletes.

The overall objective of the micro-research is to implement the concept of scientific leadership in the sport management process, focused on team motivation.

The premise is that, by exploiting the strengths of the club in close connection with the opportunities of the external environment, we can more easily optimise management processes while increasing athletic performance. Promoting managerial thinking in the formal structural organisation, anticipating and leading organisational change can be tools of particular significance in making better use of managerial resources and in increasing goal-oriented efficiency. Working hypotheses and experimenting with them as micro research forecasts.

\section{RESEARCH OBJECTIVES}

Analysis, systematization and synthesis of theoretical and methodological knowledge from the literature on:

Assessing the motivational trainability of athletes

Utilizing tests including determination of biochemical phenomena and optimization of athletes' nutrition

Emphasising the use of motivational methods.

Research Hypothesis

Working hypotheses and experimenting with them as predictors of micro-research.

In order to solve the tasks of this micro-research, the following working hypotheses were used:

General Hypothesis

If the leadership style suits the athlete and/or the group, then the athletes' performance will be superior.

Specific Hypothesis \#1

If we apply real-time scientific methods, biochemical testing and cardiometabolic testing, then we are giving a better chance to perform in swimming at European and world level.

Specific Hypothesis \#2

If the leader finds the right motivational methods for each athlete, then their performance will be on an upward trend.

\section{DESCRIPTION OF THE TARGET GROUP AND RESEARCH STAGES}

Case study conducted on 6 performance athletes in a group of 26 athletes. The micro-research was carried out between November 2020 and April 2021, on athletes in the group but also on athletes from other sports clubs.

1. PBM - aged 24, lives in an urban environment and has been training for 18 months in France in preparation for the 2021 Olympic Games. He is a sports graduate with a master's degree in organisation and management. His parents had a painful divorce when he was 10 , he was raised by his father from the age of 14 . He is currently experiencing health problems and going through a difficult emotional period after his father's death in November 2020. He has no solid financial support which is burdening him emotionally. Emotional and economic needs are most important. First of all, he needs to improve his 
health in order to be able to continue his athletic training for the final qualifying tournament. A qualification can ensure both emotional and financial stability. Interventions are being carried out, but they are time-limited. Those who act are actively involved and their main aim is to restore self-confidence and a state of physical and mental health that is optimal for performance. The coordination of collaborative sports activity started at the age of 11 . He has a predominantly sanguine temperament.

2. ȘS - aged 16, lives in Ploiesti, trains in urban areas and is looking for promotion to the top junior team. He is a high school student, his mental strength declined during the pandemic, he went through the virus that stopped the world in its tracks and after a break, to recover physically from the virus, he resumed his activity eager to achieve his goals. He has 3 older brothers, father works abroad. He has a predominantly melancholic temperament. We have been coordinating his athletic training for 3 years.

3. UOF - aged 14, living and training in an urban environment, understood that her native talent could not bring him success in sport without proper involvement. His father works abroad, his mother in Bucharest and he is cared for by his grandmother. He has a predominantly phlegmatic temperament. I've been training him for 2 years.

4. LC - 14 years old, lives in the countryside, commutes to play competitive sports. He has been in the group for a year now, his temperament is mainly phlegmatic.

5. NA - 14 years old, lives in an urban environment, practices competitive sports at the urging of his grandfather, a former contact sports coach. We believe that she does not want to practice a competitive activity and progress comes very slowly, because the involvement in training is very low. She has been in the group for 2 years. She has a predominantly melancholic temperament.

6. CA - 13 years old, lives in an urban environment, came to the group 2 years old. The pandemic also had a positive aspect, as her mother and grandmother no longer have access to training and competitions and the sportswoman released stress from inappropriate observations and in this way managed to achieve significant progress in a short period of time. She has a predominantly sanguine temperament.

There are other talented athletes in the group, but all the tests were done without the support of the club, and only because of the desire and financial support of the coach and parents. After paying more attention to the athletes actively involved in micro-research, the other athletes have also become more attentive and participate with greater interest in the sports activity.

\section{DESCRIPTION OF RESEARCH INSTRUMENTS AND TARGET GROUP}

We used the case study method to track the performance of the 6 athletes.

The Questionnaire Research Survey method is a technique, an investigative tool consisting of a set of written, logically ordered questions which, when applied, elicits from research participants responses that are recorded and analysed in the research of a subject. The questionnaires were applied to 11 managers, 11 coaches, 33 athletes from state and private sports clubs in Romania.

Observation method: Observation Sheet - we developed 8 behaviours that we observed in the 26 athletes we worked with during the micro-research.

The evaluation grid (initial and final) of the athlete's behaviour with the observed behaviours helped us through its regulatory role both in the athletes' training activity and in the improvement of sport strategies. 
Testing method: Biochemical testing - the identification of biochemical phenomena that occur during physical exercise is of particular importance in the process of scientific physical exercise practice. Sporting activity involves physical exertion of varying intensities, which include "a higher energy consumption than the energy consumption required during normal vital processes". Basal metabolism, which is also called resting energy metabolism, represents the energy balance of a resting body.

The testing method: Cardiometabolic testing on nutrition optimization in swimming - during effort, it will establish the elaborated determination of effort thresholds and certain nutritional modifications may be required, such as the satisfaction of energy requirements and the establishment of a starting point for the elaboration of dietary plans in relation to sports effort.

\section{RESULTS AND INTERPRETATION}

The first item in the questionnaire reveals that the majority (73\%) of managers consider that they use the democratic style and only $9 \%$ consider that they use the authoritarian style. From the discussions with the participants who were asked to explain the reasons for their answers, we believe that depending on the people involved in the performance process, the two management styles are used - democratic for those $100 \%$ involved, and authoritarian for the athletes who need to be constantly pushed.

At the beginning of an athlete's activity, a coach must use a predominantly democratic teaching style in order to attract the student athlete towards competitive activity. The majority (9 out of 11) of the respondents indicated in item 2 that the leadership style adopted in leading the groups they have to coach is very important.

In item 3 where we asked respondents to choose a skill that sets a manager apart from other managers in terms of performance, $45 \%$ of respondents felt that transparency in decision making is important in management and only $18 \%$ felt that the ability to handle situations correctly would set them apart from other managers. The sports management system is seen as suffering from a lack of transparency. What is right for an individual or a group cannot be decided by the manager alone.

In item 4 the respondents had to rank the 3 most important components of sports training in their personal opinion, and the majority of the respondents believe that sports nutrition plays a very important role in achieving sports performance and only next in importance are sports training and mental training, with biochemical testing being less valued by managers/coaches in achieving top level performance. Cardiometabolic testing is less appreciated because it is also less familiar.

Asked to list what improvements they would bring to the sports club, the respondents (managers) believe that an efficient sports base would encourage more children to play sports. All of them would like to see a bigger budget but also collaboration with teams of specialists to guide the managerial process in sports coaching. At the same time, the budget should be allocated according to performance.

Asked to identify the most important element that brings athletic performance to world level, they also mentioned the development of a strategy to achieve performance objectives and the contribution of a technical team of specialists to performance. In the strategy for achieving world-class performance, an 8-year plan with individualised objectives should be developed. A lower percentage is given in the respondents' opinion to the coordination of the group focusing on performance. 
In item 9, the respondents consider it very important to motivate coaches and athletes through material stimuli, but also stimuli aimed at appreciation, confidence and active participation in a long and difficult process until performance is achieved.

In item 10 the role of public relations is rated as very important and is carried out through the sports advisor who supports and facilitates the performance activity.

And in item 11, most respondents do not give us any encouraging feedback. The answers show a situation that puts the educational process at a standstill because the majority of them consider that the local authorities are not interested in solving the problems of the sports club, which clearly reflects the reality.

For item 2 in the coaches' questionnaires, respondents' perceptions ranked first the coach's competence, the material base and, on a par, the training methods and the budget allocated to the team of athletes, when asked to list the three most important components of sports training to achieve performance.

In item 4 , in the selection of technical team members the coach obviously comes first in the technical team. At international level, athletes cannot achieve top performance without the advice of a psychologist. A coach cannot do it all alone, each specialist has their role in achieving an athletic result.

More than $90 \%$ of respondents rated practical experience in coaches as more important than overall specialist knowledge. Also, 10 out of 11 respondents felt that managerial style influences athletic performance.

Item 7 addressed to the coaches deals with the disadvantages they have noticed in the club where they work and the most frequent were - lack of coaching staff, lack of community interest and investment, lack of a selection system, family support, etc. In Romania, sports facilities leave something to be desired or they are altogether missing. Clubs cannot have a team of coaches and only very few coaches and athletes reach senior level, so that the competent bodies could invest in them. The selection system is almost non-existent. Without the support of the athlete's family, they cannot participate in training. Parents play an important motivational role during an athletic performance.

In item 8 , respondents consider that the positive influence of managers plays a lesser role in achieving performance, the most important being the material base and the budget. The bio-physical profile of the athlete is important.

Item 9 addresses the respondents' opinion on the role of extrinsic motivation in setting an upward trend in performance, and the majority of coaches surveyed considered extrinsic motivation to be paramount. I believe that intrinsic motivation is more important, as a result must be achieved first and then extrinsic benefits follow.

Athletes, as respondents in the third category, consider in item 2 that they are motivated to participate in training, and are willing to go through a difficult training process as a way to perform. Athletic results grant one a special status in one's environment.

The majority of respondents considered the role that the coach plays in their lives to be very important, beneficial, useful and decisive. The percentage rating of the role the coach plays in the athlete's life is encouraging and at the same time empowering for the coach who receives such praise. It is very important for the athlete to find the sport and the coach that will propel them to great performance. The coach is a guide, a trainer, a mentor but also a moral support.

In terms of the top 2 most appreciated qualities in a coach, the majority of respondents chose commitment, confidence, passion, motivation. After parents, the coach is 
the most important person in the athlete's life and the more they are appreciated the more they are dedicated, confident, passionate, a motivating factor. The majority of respondents felt that the joy, support and encouragement of the coach was a characteristic of their training. When respondents were asked to select 2 options of changes in their athletic activity, they frequently chose no change, then time of training, frequency of training, and athletic challenge. A very small percentage chose coach, team, other. We believe that either habit or the similarity of the coaches' qualities to those of the athletes led the respondents to consider that the coach was not among the aspects that should be radically changed.

In item 7, respondents consider intrinsic motivation to be an important aspect in the coach's planning that teaches them to overcome their physical and mental limitations by overcoming the pain threshold brought about by training.

Item 8 deals with the athletes' opinion on whether they prefer intrinsic or extrinsic motivation. Respondents felt that intrinsic motivation comes first and the coach has the ability to deal with it appropriately.

In item 9, athletes rated the importance given by coaches to biochemical and cardiometabolic testing, with the majority considering it to be very important and given great importance by coaches. Before and during training, fatigue and exertion adaptation can be determined with a device that measures lactic acid. There can be no performance without mentioning the importance of testing.

When asked to rank the top 4 elements in achieving successful sport performance respondents rated the coach, then mental training, sport training, sport nutrition, family support, specific training, coach's communication style etc.

Item 11 asks for the respondents' appreciation of the coach's style and over $63 \%$ believe that the democratic style is the most commonly applied by coaches, and the majority of athletes consider very important or important the role of this style in achieving athletic performance. Respondents believe that the coach's managerial style is important because they are role models and one cannot participate joyfully in training if the coach's influence is lacking, if there is no spark of enthusiasm.

Applying the observation sheet (5 initially observed behaviours: active participation in training, physical engagement in effort, mental engagement during effort, psychomotor concentration to elements of technique, psychomotor endurance to volume and intensity) on 26 athletes in November 2020, we looked for behaviours that we intended to refine during training, thus also improving athletic performance for the first competitions. We tracked behaviours for 60 minutes and applied motivational formulas to both the athletes involved in the micro research and the other athletes. We applied the same sheet at the end of the micro-research, after 4 months in which we applied motivational formulas to all the athletes in the group and biochemical and cardiometabolic tests to the other athletes, and we had remarkably good results both in the athletes' attitude to training and in the results obtained in competitions.

Sports Behaviour Rating Grid structured on 8 behaviours: Performs the activity at a slow pace but with sufficient accuracy; Tendency to overestimate self and underestimate task; Tendency to overestimate task but underestimate self; Does not give up in case of failure, persists resumes the task or activity from the beginning, encourages self, completes the task; In case of failure loses self, needs encouragement to resume; Remains indifferent to success, merely attempts a smile; Quits when failures accumulate; Emotional lapses under the pressure of the competition. 


\section{CONCLUSION}

$>$ A number of management theorists do not accept the argument that the key factor in the success of an organisation, club, athlete, or student, is its leadership.

$>$ Leading people is a dynamic group process whereby one person manages to influence other members of the group to willingly commit to the group's objectives over a period of time and in a particular organisational context, as in the case of our micro-research.

$>$ I assumed that if the leadership style is suitable for the athlete/group, then the athletic performance will be superior. (MARTENS, R., 1999)

$>$ This general hypothesis is confirmed, since during the micro-research we applied motivational formulas and methods on the whole team and the results were remarkable both in terms of working attitude towards training difficulties and of the results obtained.

$>$ The specific hypotheses are also confirmed, we applied cardiometabolic tests on 6 athletes and biochemical tests on one athlete, and they achieved superior performances, firstly because they were given attention and secondly because they learned how important the scientific management of training is. They understood that by applying the same stimulus to several individuals, the responses are different because we are different.

$>$ Specific hypothesis \#2 is also confirmed, by applying motivation methods appropriate to each athlete, the evolution of performance is on an upward trend.

\section{LIMITS OF THE MICRO-RESEARCH}

$>$ All cardiometabolic, biochemical, psychological, nutritional tests are very expensive and until they reach the national team, only the parents or the coach will have to support the performance and the expenses required to obtain it.

$>$ In state-owned clubs we are not allowed to have a psychologist, to have a physical trainer, to hire other specialists who can help coordinate the training process.

$>$ The financial situation of many athletes is precarious and the coach is unable to support this passion financially.

$>$ Sports performance costs money.

\section{ADVANTAGES OF THE MICRO-RESEARCH}

$>$ This study can also be applied after the termination of the micro-research carried out in this paper.

$>$ Motivating team members increases the chances of achieving exceptional results. (GLYN, C. R., 1992)

$>$ As we are talking about education, albeit through sport, we increase young people's chances of becoming adults we can rely on.

$>$ Every aspiring athlete achieves their goal if they are enthusiastic, if they carry out their work with pleasure and joy.

$>$ Somewhat surprisingly, the material factors of sporting success are not at the top of the respondents' answers, rather human factors such as the value of the athletes and the competence of the coach/manager.

\section{GENERAL CONCLUSIONS}

$>$ Sport aims to develop the individual's skills in an organised system of selection, training and competition, with the aim of improving sporting results, achieving personal and national records and winning. It is a large-scale phenomenon, capable of unleashing human energies and mobilising material and financial resources that can 
hardly be compared with those in other areas of social life, and its development has turned it into a complex industry with economic and social impact on the human community.

$>$ Sport requires a careful selection, a special scientific training and the achievement of maximum individual performances in competitions, it helps to form and perpetuate values such as fair play, hard work, effort, sacrifice, loyalty, discipline, influence.

$>$ A management style based on people development is stronger in managers who have a longer training and educational background.

$>$ The leadership style is not fixed on certain situations, it is applied predominantly to one extent or another. It depends on the situation. (Enache, 2021)

$>$ It is not the style of leadership, authoritarian or democratic, that leads to exceptional performance, but the impact that one action or other leaves on the influenced group. Each individual should understand that the manager/coach is not looking to lead, but build a partnership that will bring high performance to everyone.

$>$ Regardless of the leadership style applied, communication plays a very important role in interpersonal relationships. Where there is communication, enthusiasm, and dedication, the results are noticeable.

\section{BIBLIOGRAPHY}

[1] EPURAN, M., HOLDEVICI, I., TONITA, F., (2001), Psihologia sportului de performanta. Teorie si practica, Bucuresti, Edit. FEST.

[2] FAMOSE, J.-P., (1993), Cognition et performance. Paris, INSEP - Publications.

[3] GLYN, C. R., (1992), Motivation in sport and exercise Champaign, Illinois, Edit. Human Kinetics Books.

[4] MARTENS, R., (1999), Ghidul antrenorului in psihologia sportului. In: Sport de performanta. Bucuresti, INCS, nr. 413-418.

[5] ENACHE, R., (2021), Evaluarea programelor educaționale, Note de curs, DPPD-UTCB. 